\title{
Production of a hypothetical polyene substance by activating a cryptic fungal PKS-NRPS hybrid gene in Monascus purpureus
}

\author{
Jae-Won Suh ${ }^{1} \cdot$ Bijinu Balakrishnan ${ }^{1}$ (D) $\cdot$ Yoon Ji Lim ${ }^{1} \cdot$ Doh Won Lee $^{1} \cdot$ \\ Jeong Ju Choi ${ }^{1} \cdot$ Si-Hyung Park ${ }^{2} \cdot$ Hyung-Jin Kwon ${ }^{1}$

\section{홍국Monascus purpureus에서 진균 PKS-NRPS 하이브리드 유전자의 발현 유도를 통한 미지 polyene 화합물의 생성}

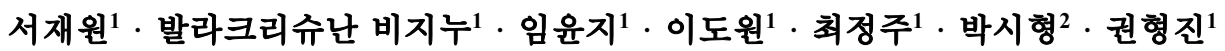

Received: 6 February 2018 / Accepted: 6 March 2018 / Published Online: 31 March 2018

(C) The Korean Society for Applied Biological Chemistry 2018

\begin{abstract}
Advances in bacterial and fungal genome mining uncover a plethora of cryptic secondary metabolite biosynthetic gene clusters. Guided by the genome information, targeted transcriptional derepression could be employed to determine the product of a cryptic gene cluster and to explore its biological role. Monascus spp. are food grade filamentous fungi popular in eastern Asia and several genome data belong to them are now available. We achieved transcription activation of a cryptic fungal polyketide synthase-nonribosomal peptide synthase gene Mpfus I in Monascus purpureus $\triangle M p P K S 5$ by inserting Aspergillus gpdA promoter at the upstream of Mpfus 1 through double crossover gene replacement. The gene cluster with Mpfus1 show a high similarity to those for the biosynthesis of conjugated polyene derivatives with 2-pyrrolidone ring and the mycotoxin fusarin is the representative member of this group. The $\triangle M p P K S 5$ is incapable of producing azaphilone pigment, providing an
\end{abstract}

Hyung-Jin Kwon $(\bowtie)$

E-mail: hjink@mju.ac.kr

${ }^{1}$ Department of Biosciences and Bioinformatics, Myongji University, Yongin-si, Gyunggi-do 17058, Republic of Korea

${ }^{2}$ Department of Oriental Medicine Resources and Institute for Traditional Korean Medicine Industry, Mokpo National University, Muan-gun, Jeollanam-do 58554, Republic of Korea

This is an Open Access article distributed under the terms of the Creative Commons Attribution Non-Commercial License (http://creativecommons. org/licenses/by-nc/3.0/) which permits unrestricted non-commercial use, distribution, and reproduction in any medium, provided the original work is properly cited. excellent background to identify chromogenic and UV-absorbing compounds. Activation of Mpfus 1 resulted in a yellow hue on mycelia and its methanol extract exhibit a maximum absorption at $365 \mathrm{~nm}$. HPLC analysis of the organic extracts indicated the presence of a variety of yellow compounds in the extract. This implies that the product of MpFus1 is metabolically or chemically unstable. LC-MS analysis guided us to predict the MpFus1 product and to propose that the Mpfusl-containing gene cluster encode the biosynthesis of a desmethyl analogue of fusarin. This study showcases the genome mining in Monascus and the possibility to unveil new biological activities embedded in it.

Keywords Activation of cryptic gene $\cdot$ Aspergillus gpdA promoter $\cdot$ Double crossover gene replacement $\cdot$ Fusarin analogue - Monascus purpureus · Polyketide synthase-nonribosomal peptide synthase hybrid

\section{서 론}

홍국균(Monascus spp.)은 자주색 계열에 가까운 붉은 색소를 생 산하는 적색 누룩곰팡이로 널리 알려져 있으며, 오래 전부터 동 아시아 지역에서 발효 식품인 홍국미를 만들 때 사용되어왔다 (Chen 등, 2015). 홍국균이 생산하는 홍국 색소는 식용 색소로 사용되고 있으며, 화학적으로는 azaphilone 계열에 속하고 노랑, 주황 및 적색의 세가지 색으로 구분할 수 있다(Chen 등, 2015). 홍국 색소의 생합성 기작은 해당 생합성 유전자를 활용한 분자 
생화학적 연구를 통하여 밝혀졌다(Balakrishnan 등, 2013; 2014; Bijinu 등, 2014; Balakrishnan 등, 2017a; 2017b; 2017c; Chen 등, 2017). 이외에도 홍국균은 콜레스테론 생합성 저해제 인 monacolin $\mathrm{K}$ 와 진균 독소인 citrinin의 생산 균주로 잘 알려 져 있다(Patakova 등, 2013). 식용 진균으로서의 중요성에 착안 하여 몇 몇 홍국 균주들에 대한 유전체 서열 결정이 완료되었 으며, Monascus purpureus NRRL 1596와 Monascus ruber NRRL 1597의 유전체 서열 정보가 U.S. Department of Energy Joint Genome Institute (DOE-JGI)의 web page에 공 개되어 있다. 이 정보를 활용하여 M. ruber NRRL 1597 균주 는 citrinin 생합성 능력이 없으며, M. purpureus NRRL 1596 의 경우 monacolin $\mathrm{K}$ 생합성 유전자군이 소실되었음을 확인할 수 있다(Kwon 등, 2016).

미생물들의 유전체에는 미지 이차대사산물의 생합성을 지정 하는 유전자군이 다수 존재하며, 이들 정보를 활용하여 새로운 생리활성물질을 발굴하는 연구 전략이 제시되고 있다(Medema 와 Fischbach 2015; van der Lee와 Medema 2016). 이러한 연구 전략은 생합성 유전자군에서 지정하는 개별 생합성 효소 들의 기능 추론에 근거하며, 이러한 측면에서 가장 진보된 분 야가 polyketide 생합성 경로라고 할 수 있다. 본 연구의 대상 인 홍국균을 포함하는 사상균 영역에서도 유전체 정보에 기초 한 polyketide 생합성 경로 발굴이 활발히 수행되고 있다 (Chiang 등, 2010; Yin 등, 2016). 진균 polyketide 생합성 경 로 중에는 아미노산과 펩티드 결합을 통하여 탄소 골격 형성이 완료되는 부류가 알려져 있으며, 이들의 생합성은 반복적으로 작용하는 fungal polyketide synthase (fPKS) 모듈에 non-ribosomal peptide synthase (NRPS) 모듈이 결합된 형태인 fPKS-NRPS 하이브리드 효소에 의하여 이루어진다(Boettger와 Hertweck 2013; Fisch 2013). fPKS-NRPS의 PKS모듈은 일반적으로 highly reducing (HR)-fPKS의 도메인구성을 취하고 있다. $\mathrm{HR}$ fPKS는 $\beta$-ketoacyl-acyl carrier protein (-ACP) synthase (KS), acyltransferase (AT), $\beta$-hydroxyacyl-ACP dehydratase (DH), $C$-methyltransferase (MT), $\beta$-ketoacyl-ACP reductase (KR), trans-2-enoyl-ACP reductase (ER) 및 $\mathrm{ACP}$ 도메인을 포함한다. 그러나 ER 도메인이 모듈 내에 존재하지 않는 $\mathrm{HR}-\mathrm{fPKS}$ 의 예 가 다수 알려져 있으며, 이 경우에는 독립적인 단백질로 존재 하는 ER효소가 생합성 과정의 특정 주기에 선택적 환원 과정 을 촉매한다(Cox 2007). fPKS는 하나의 모듈로 구성되어 반복 적인 acetate 단위체 축합 및 변형과정을 촉매하며 이 때 $\mathrm{ER}$ 활성과 함께 MT 활성도 특정 축합 주기에서 선택적으로 작용 하는 특성 또한 잘 알려져 있다. fPKS-NRPS의 경우 NRPS 모 듈은 전형적인 condensation $(\mathrm{C})$, adenylation (A) 및 thiolation (T) 도메인 구성과 함께 말단 방출 도메인으로 구성되어 있다. PKS나 NRPS 생합성에서 가수분해 방출(thioesterase) 도메인을 통한 carboxylate 형태의 방출 이외에 환원 방출(R) 도메인을 통하여 aldehyde 또는 alcohol 형태로 방출되는 예 또한 보고된 바 있다(Li 등, 2008; Boettger와 Hertweck 2013; Barajas 등, 2015). 환원 방출 도메인을 통하여 aldehyde 형태로 방출되는 fPKS는 홍국색소를 비롯한 azaphilone polyketide 경로에서 실 증된 바 있다(Zabala 등, 2012; Bijinu 등, 2014).

M. purpureus 유전체(http://genome.jgi.doe.gov/Monpu1/Monpu1. home.html)에서 두 개의 fPKS-NRPS 유전자군의 존재를 확인
할 수 있다; protein ID 471657 또는 510292의 유전자를 포함 하는 유전자군. 이중 protein ID 417657 유전자(본 연구에서 Mpfus 1 으로 지칭함)를 포함하는 fPKS-NRPS 유전자군은 유전 자 구성 측면에서 Fusarium 진균 독소 fusarin의 생합성 유전 자군(Niehaus등, 2013)과 높은 유사성을 갖고 있다(Fig. 1). 본 연구에서는 Mpfusl를 포함하는 fPKS-NRPS 유전자군이 지정하 는 대사산물을 추론하고자 Mpfus1 상단에 외부 promoter를 삽 입하는 방식으로 전사 유도를 달성하였다. 해당 재조합 균주에 서 유도된 노란색 화합물의 특성 분석 결과와 이를 바탕으로 한 구조 예측을 본 논문에서 제시한다. 본 연구는 식용 진균인 홍국의 이차대사 잠재능력에 대한 인식을 확장하는 기회가 될 것으로 기대된다.

\section{재료 및 방법}

\section{균주 배양 및 추출 조건}

본 연구에서는 Monascus purpureus Korean Agricultural Culture Collection (KACC) 42430이 사용되었다. M. purpureus 야생형 과 파생형 균주들을 potato dextrose agar (PDA)에 접종하여 $30{ }^{\circ} \mathrm{C}$ 에서 5-7일간 배양되었다. PDA 배지의 부피는 약 $50 \mathrm{~mL}$ 를 유지하였으며, PDA 배양체의 추출은 methanol을 사용하여 진행하였다. 이후 methanol 추출액에 $1 / 2$ 부피의 chloroform을 가하여 층 분리를 달성하였다. 일반적인 경우 methanol 추출액 에 잔존하는 물에 기인하여 층 분리가 자연스럽게 이루어지지 만, 층 분리가 원활하지 않을 경우 증류수를 적정량 첨가하는 방식으로 층 분리를 유도하였다. 이 후 얻어진 chloroform 층을 취하여 감압 건조한 후 methanol에 녹여 화학 분석에 적용하였 다. PDA 배양체를 활용하여 potato dextrose broth (PDB)에서 액체 배양을 진행하였다. $\mathrm{PDB}$ 배양에서는 $50 \mathrm{~mL}$ 배지를 250 $\mathrm{mL}$ 주름 플라스크에 적용하여 $30^{\circ} \mathrm{C}$ 에서 $5-7$ 일간 $250 \mathrm{rpm}$ 조 건에서 현탁 배양하였다. 얻어진 배양체에서 원심분리 $(7,000$ $\mathrm{rpm} ; 4{ }^{\circ} \mathrm{C}$; 30 분)를 통하여 균사체를 획득한 후 $\mathrm{PDA}$ 배양체 추출과 동일한 방법으로 methanol 추출을 수행하고 chloroform 층 분리를 통하여 농축 시료를 획득하였다.

\section{M. purpureus fPKS-NRPS 유전자 Mpfus1 발현 유도}

재조합 플라즈미드 작성을 위한 PCR 프라이머 작성에는 DOE-JGI M. purpureus 유전체 server (http://genome.jgi.doe.gov/Monpul/ Monpu1.home.html) 정보를 활용하였다. 해당 정보에서 Mpfus1 는 scaffold_14:120754-132756의 (-)-strand에 해당한다. Mpfus1 의 발현 유도는 Mpfus1 upstream 영역에 Aspergillus nidulans $g p d A$ promoter (gpdAp; Redkar 등, 1998)를 삽입하는 방식으 로 달성하였다. 이중교차 상동재조합를 통한 $g p d A p$ 삽입을 위 하여 삽입 위치 upstream과 downstream 영역의 DNA 서열을 증폭하여 재조합 플라즈미드를 작성하였으며, 바탕 벡터는 pCambia1300 (GenBank accession no. AF234296)을 사용하였 다. 본 연구에 사용된 DNA 프라이머들은 Table 1에 제시하였 다. $g p d A \mathrm{p} \mathrm{DNA}$ 는 $2.1 \mathrm{~kb}$ 이며, $\mathrm{pUR} 5750$ 에서 발췌하여 사용 하였다(de Groot 등, 1998). $g p d A p$ 삽입 재조합 균주를 선별하 기 위하여 neomycin 저항성 유전자 조합체(nptII)를 $g p d A \mathrm{p}$ 와 연결하여 재조합 플라즈미드 작성에 사용하였다. $2.8 \mathrm{~kb} n p t I I$ 는 
Table 1 Primers used in this study. The nucleotide sequences introduced for cloning process are italicized

\begin{tabular}{ll}
\hline \hline \multicolumn{1}{c}{ Primer name } & \multicolumn{1}{c}{ Sequence $(5 \rightarrow 3)$} \\
\hline PgpdA-F & GAATTC ACTGAAATACGTCGAGCCTG \\
PgpdA-R & AGATCT GTAGCTGTTAGTCAAGCTGC \\
MpFus1-Up-F & CCATGATTACGAATTC AATGCGAATAGCGTCCTCTG \\
MpFus1-Up-R & TTGACTAACAGCTAC CATCGGATTGCCCTATGCTA \\
MpFus1-NptII-PgpdA-F & GTAGCTGTTAGTCAAGCTGC \\
MpFus1-NptII-PgpdA-R & CAAGCTCTATGGGGC GGATTACCTCTAAACAAGTG \\
MpFus1-Dw-F & GCCCCATAGAGCTTGGTTGG \\
MpFus1-Dw-R & TACCGAGCTCGAATTC ACTGGGCCCATGATTTCATG \\
MpFus1-confirm-F & ATGGCATCCCAGAGCTTGGA \\
MpFus1-confirm-R & AGTAATAAGCCACTGGCCAG \\
\hline
\end{tabular}

Aspergillus nidulans trpC promoter와 trpC terminator를 활용 하여 제조된 조합체이며, pII99에서 발췌하여 사용하였다(Namiki 등, 2001). nptII에 상응하는 저항성 형질전환체 선발은 $\mathrm{G}-418$ (geneticin)을 활용하여 수행하였다.

$g p d A \mathrm{p}$ 와 $n p t I I$ 조합체의 제조를 위하여 $g p d A \mathrm{p}$ DNA를 PgpdA$\mathrm{F} /-\mathrm{R}$ 프라이머 쌍을 이용하여 pUR5750 DNA에서 PCR로 증폭 하였다. 본 실험의 모든 PCR 증폭은 Hurculase II fusion polymerase (Agilent, Santa Clara, CA, USA)를 사용하였다. PgpdA-F, -R 프라이머 각 각에 EcoRI, $B g l I I$ 절단 서열을 도입 하였으며 PCR 증폭 후 Ex Tag polymerase (Takara, Dalian, China)를 처리하는 방식으로 A-tailing을 유도하고, T-vector cloning를 달성하였다. T-vector에 삽입된 $g p d A \mathrm{p} \quad \mathrm{DNA}$ 를 EcoRI-BglII 단편으로 분리한 후 pII99의 polycloning site에 존 재하는 EcoRI, $B g l I I$ 서열 사이에 삽입하였다. 이를 통하여 작 성된 $\mathrm{pJWS1}$ 플라즈미드는 $n p t I I-g p d A \mathrm{p}$ 를 포함하게 된다.

상동재조합을 위한 upstream $(2,147 \mathrm{bp})$, downstream $(1,983$ $\mathrm{bp)}$ 단편은 각 각 Mpfus1-Up-F/-R, Mpfus1-Dw-F/-R 프라이머 쌍을 이용하여 M. purpureus KACC 42430 total DNA 에서 $\mathrm{PCR}$ 증폭으로 확보하였다. $n p t I I-g p d A \mathrm{p}$ 단편은 $\mathrm{pJWS} 1$ 으로부 터 MpFus1-NptII-PgpdA-F/-R 프라이머 쌍을 이용하여 PCR 증 폭하였다. 얻어진 세 개의 DNA 절편을 In-Fusion cloning (Clontech, Mountain View, CA, USA) 기법을 활용하여 pCambia1300의 EcoRI 위치에 삽입하여 pJWS2를 제조하였다. Agrobacterium을 활용한 형질전환 기법을 통하여 $\mathrm{pJWS} 2$ 를 $M$. purpureus DMpPKS5에 도입하였으며(Balakrishnan 등, 2013), $\mathrm{G}-418$ 에 대한 저항성을 통하여 형질전환체를 일차 선발하고 $\mathrm{PCR}$ 검정을 통하여 이중교차 상동재조합 균주를 동정하였다.

\section{화학 분석}

HPLC 분석은 ProStar System (Varian, Palo Alto, CA, USA) 에 Gemini $\mathrm{C} 18$ 분석 컬럼 $(5 \mu \mathrm{m}, 3.0 \times 150 \mathrm{~mm}$; Phenomenex, Torrance, CA, USA)을 장착하여 수행하였다. 자외선 검출 파장 은 $350 \mathrm{~nm}$ 로 지정하였으며, 증류수와 acetonitrile을 사용한 용 매 비율 기울기 용출을 분당 $0.5 \mathrm{~mL}$ 의 속도로 진행하였다. 기 울기 용출 조건은 다음과 같다. 5 분간 $100 \%$ 의 증류수로 유지 한 후, 20 분 동안 $100 \%$ 의 증류수에서 $100 \%$ acetonitrile로 용 매 비율 기울기를 적용하였으며 이 후 10 분간 $100 \%$ 의 acetonitrile로 유지하였다.
HPLC-mass spectrometry (-MS) 분석은 Dionex UltiMate 3000 UHPLC (Thermo Scientific, Sunnyvale, CA, USA)와 결합된 LTQ XL Orbitrap mass spectrometer (Thermo Scientific, Bremen, Germany)를 사용하여 수행되었다. Electrospray 이온화 는 양이온, 음이온 검출 방법 모두에서 수행되었고 $\mathrm{m} / \mathrm{z} \quad 300-500$ 영역에서 이온 분포를 관찰하였다. 시료는 reverse-phase Kinetex column $(1.7 \mu \mathrm{m}, 2.1 \times 100 \mathrm{~mm}$; Phenomenex, Torrance, CA, USA) 에 주입하였고 이동상은 증류수와 methanol을 사용하였다. 용출 속도는 분당 $0.2 \mathrm{~mL}$ 로, 온도는 $40{ }^{\circ} \mathrm{C}$ 를 유지하였다. 다음과 같 은 용매 비율 기울기 프로그램으로 용출을 진행하였다: 10 분간 $2 \%$ 의 methanol을 유지한 후, 30 분 동안 $100 \%$ 의 증류수에서 $100 \%$ methanol로 용매 비율 기울기를 적용하였으며 이 후 10 분간 $100 \%$ methanol을 유지하였다.

\section{결과 및 고찰}

Monascus purpureus에서 fusarin 유사체 생합성 유전자군 분석 본 연구에서는 M. purpureus 유전체 정보(http://genome.jgi.doe. gov/Monpu1) 탐색을 통하여 동정된 특정 fPKS-NRPS (protein ID 471657) 유전자(scaffold_14:120754-132756의 (-)-strand; 본 연구에서 Mpfusl으로 지칭함)에 대한 유전자 발현 유도를 수행 하였다. Mpfus1 유전자군에 포함된 개별 유전자들의 유추 기능 은 Fusarium fujikuroi 유래 진균 독소 fusarin의 생합성 유전자 들(Díaz-Sánchez 등, 2012; Niehaus 등, 2013)과 높은 유사성 을 보임을 확인할 수 있다(Fig. 1). Fusarin 생합성 유전자 불활 성화 연구를 통하여 4개의 유전자 fus $1, f u s 2, f u s 8$ 및 fus 9 이 fusarin 생합성을 지정함이 실증 되었으며(Niehaus 등, 2013), fus 1 fPKS-NRPS 유전자와 높은 유사성을 보이는 Mpfus1 유전 자 주위에 fus $2, f u s 8$ 및 fus 9 과 유사성을 보이는 유전자들도 존 재함을 확인할 수 있다(Fig. 1). Fus1 fPKS-NRPS의 fPKS 모 듈은 ER 도메인이 부재하여 conjugated polyene 골격을 생산하 며, 약 $365 \mathrm{~nm}$ 영역에서 최대 흡수를 보이는 노란색 물질이 생 합성된다(Díaz-Sánchez 등, 2012; Niehaus 등, 2013). Fusarin 의 개략적인 생합성 경로를 제시하면 Fig. 2와 같다(Niehaus 등, 2013). 이상의 정보는 Mpfus 유전자군이 fusarin과 유사한 구조 를 보유한 노란색 화합물의 생합성을 지정할 가능성을 시사하 여 준다. 참고로 Monascus 종에서 fPKS-NRPS 생성물이 보고 
(A) Fusarium fujikuroi

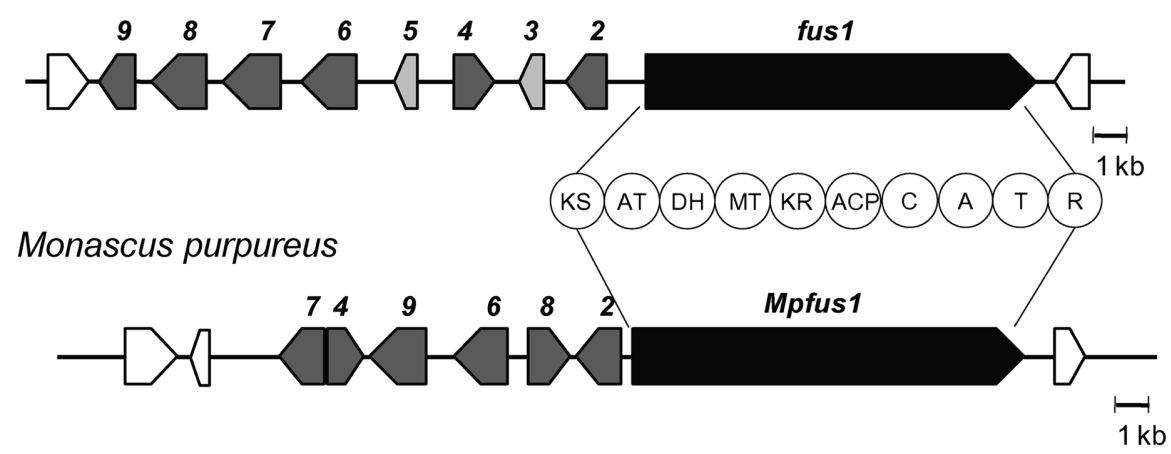

(B)

\begin{tabular}{|cccc|}
\hline $\begin{array}{c}\text { The fus gene } \\
\text { name } \\
\text { in F. fujikuroi }\end{array}$ & Predicted function & $\begin{array}{c}\text { Proposed role } \\
\text { in fusarin biosynthesis }\end{array}$ & $\begin{array}{c}\text { Identity/similarity (\%) of the fus product } \\
\text { to the homologs in } M \text {. purpureus }\end{array}$ \\
\hline fus 1 & fPKS/NRPS & backbone synthesis & $46 / 63$ \\
fus 2 & hydrolase & 2-pyrrolidone ring formation & $57 / 70$ \\
fus 3 & glutathione S- & not essential & not found \\
transferase & peptidase A1 & notessential & $35 / 50$ \\
fus 5 & serine hydrolase & not essential & not found \\
fus 6 & transporter & not essential & $60 / 77$ \\
fus 7 & dehydrogenase & not essential & $41 / 60$ \\
fus8 & cytochromeP450 & hydroxylation & $56 / 73$ \\
fus9 & methyltransferase & methylation & $44 / 62$ \\
\hline
\end{tabular}

Fig. 1 Structure of the Mpfus1 fPKS-NRPS gene cluster from Monascus purpureus (A) Comparison with the fusarin biosynthesis gene cluster from Fusarium fujikuroi (Niehaus et al. 2013). (B) The deduced function of the fusarin biosynthetic genes and the comparison to homolog found in the Mpfus l gene cluster

된 예는 아직 없다.

\section{Monascus purpureus에서 fPKS-NRPS 유전자 Mpfus1의 발현 유도}

Mpfus 1 유전자군이 지정하는 미지 화합물에 대한 정보를 취득 하기 위하여 Mpfusl upstream 영역에 gpdAp (Redkar 등, 1998)를 삽입하였으며, gpdAp 삽입 균주를 선별하기 위하여 neomycin 저항성 유전자 조합체(nptII)를 활용하고 G-418에 대 한 내성을 통하여 형질전환체를 선발하였다. 이때 $M$. purpureus 야생주 대신 홍국 색소 생합성 능력이 소실된 $\triangle M p P K S 5$ 균주 를 숙주로 사용하였다. $\triangle M p P K S 5$ 균주는 홍국 색소 생합성 fPKS 유전자의 일부를 제거한 후 해당 영역에 hygromycin 내 성 유전자 세트를 대치하는 이중교차 유전자 치환을 통하여 생 성된 균주이다(Balakrishnan 등, 2013). 해당 균주는 홍국 색소 이외의 이차대사 생합성 경로 연구에 활용 가치가 있다 (Balakrishnan 등, 2016).

$M p f u s 1$ 유전자 상단에 $g p d A p$ 를 삽입하기 위하여 제조된 pJWS2 플라즈미드는 삽입 목표 위치 양측으로 약 2-kb $M$. purpureus DNA 단편을 장착하여 이중교차에 의한 상동재조합 이 가능하도록 제조되었다. pJWS2의 형질 전환을 통하여 $\triangle M p P K S 5$ 균주에서 gpdAp-Mpfus1 균주를 제조하였으며, 해당
균주의 유전자형을 PCR을 통하여 확인하였다(Figs. $3 \mathrm{~A}, \mathrm{~B})$. 유 전형 검증에 사용된 MpFus1-confirm-F/-R 프라이머 쌍은 $g p d A \mathrm{p}$ 삽입 목표 위치 양측 서열을 참조하여 550-bp 단편이 증 폭되도록 제조되었다. 예측된 바와 같이 $\triangle \mathrm{MpPKS5}$ 균주에서 550-bp 단편이 명확히 증폭된 반면 gpdAp-Mpfus1 균주에서는 해당 단편의 증폭을 관찰할 수 없었으며 $n p t I I-g p d A p$ 서열의 삽 입에 일치하는 $5.5-\mathrm{kb}$ 단편이 증폭됨을 확인할 수 있었다(Fig. $3 \mathrm{~B})$. PDA 생장에서 gpdAp-Mpfus1 균주는 $\triangle M p P K S 5$ 에 구별되 는 발달 특징은 보이지 않았으나, 균사체에 노란색을 띄는 것 으로 관찰되었다(Fig. $3 \mathrm{C}$ ). 해당 색소 물질이 한천 배지로 퍼져 나가는 성질은 관찰되지 않았다. PDA 배양체를 methanol로 추 출하여 자외선-가시광선 흡광 스펙트럼을 조사한 결과 $365 \mathrm{~nm}$ 에서 최대 흡수도를 보이는 물질(들)이 gpdAp-Mpfus 1 균주에서 생성되었음을 확인할 수 있었다(Fig. 3D). Methanol 추출액에서 chloroform 층 분리로 얻어진 시료에서 흡수 경향이 보다 선명 함을 확인하였다. 이를 종합하여 MpfusI는 (사용된 배양 조건 에서) M. purpureus에서 발현되지 않는 유전자이며, Mpfus 1 이 지정하는 fPKS-NRPS는 $365 \mathrm{~nm}$ 영역에서 최대 흡광도를 보이 는 탄소 골격을 합성한다는 것을 제안할 수 있다. 이러한 흡광 스펙트럼은 fusarin 유사체에서 예측되는 특성 임을 강조할 필 요가 있다. 


\section{fusarin fPKS-NRPS}

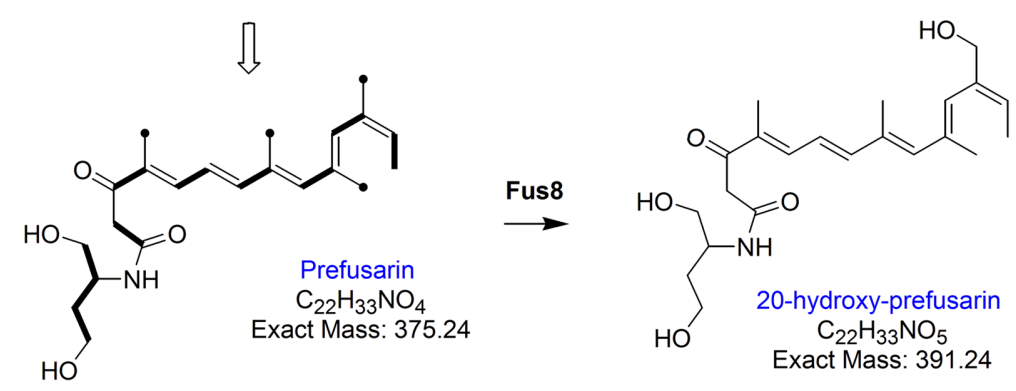<smiles>C/C=C(\C=C(C)\C=C(/C)C=CC=C(C)C(=O)[C@@]12O[C@@H]1C(O)(CCO)NC2=O)C(=O)O</smiles>

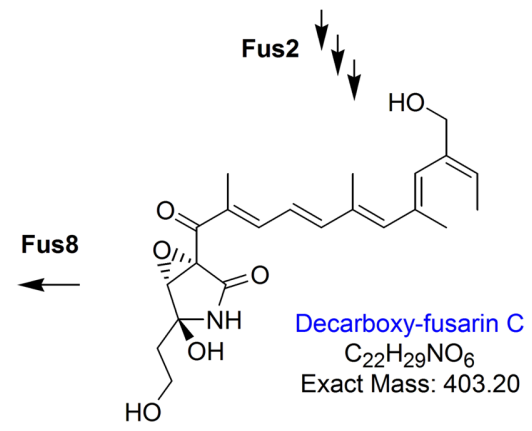

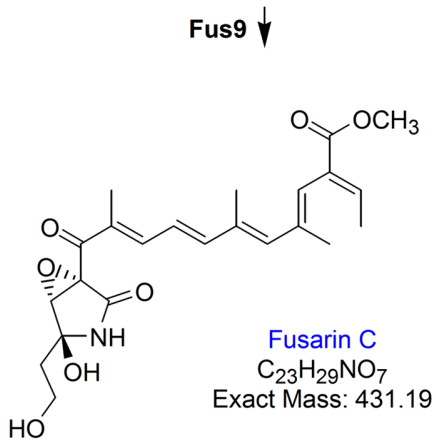

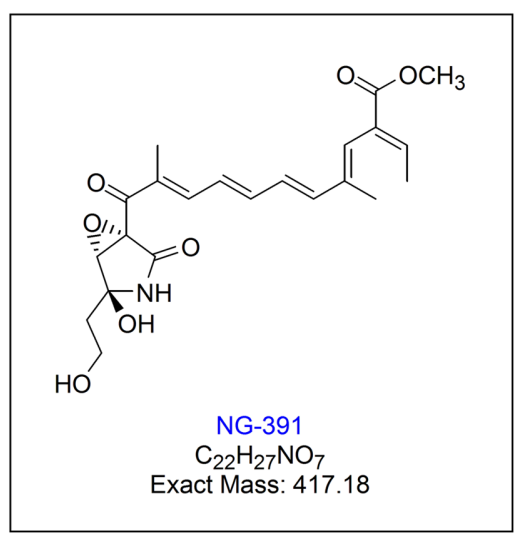

Fig. 2 Proposed biosynthetic pathway of fusarin in Fusarium fujikuroi (Niehaus et al. 2013) and the structure of NG-391. Bold lines denote acetate units and L-homoserine. Black circles indicate $S$-adenosyl methionine-derived carbons introduced by methyltransferase activity

\section{gpdAp-Mpfus1 추출액의 크로마토그래피 분석}

$\mathrm{HPLC}$ 를 통하여 추출액을 분석하였으며, 이 경우 $\mathrm{PDB}$ 현탁 배 양을 포함하였다. PDB 배지는 Ventech Bio (대한민국, 충북, 음성군) 회사의 Gellix ${ }^{\mathrm{TM}}$ 제품과 Kisan Bio (대한민국, 서울, 서 초구) 회사의 $\mathrm{MBcell}^{\mathrm{TM}}$ 제품을 사용하였다. PDA와 Gellix ${ }^{\mathrm{TM}}$ $\mathrm{PDB}$ 배양 추출액의 경우 유사한 경향을 보이며, gpdAp-Mpfus 1 균주에서 다양한 화합물들의 혼합체가 존재함을 확인할 수 있 었다(Fig. 4). 이 중 21.5분 영역에서 검출된 피크를 주된 생성 물로 파악하여 MFUS1이라 지칭하였으며, 다양한 피크의 검출은 $\mathrm{MpFus1}$ 생성물의 대사 불안전성을 암시하여 준다. $\mathrm{MBcell}^{\mathrm{TM}}-\mathrm{PDB}$ 배양 추출액의 경우 피크 분포가 크게 다름을 관찰할 수 있으 며 이는 MpFus1 생성물의 대사 불안전성을 지지하는 현상으로 파악된다(Fig. 4).
반복 실험을 통하여 Gellix ${ }^{\mathrm{TM}}-\mathrm{PDB}$ 배양에서 MFUS1 생성에 재현성이 있음을 확인하였으며, 대량 배양을 통하여 이 화합물 의 분리 동정을 시도하였으나 구조 분석이 가능한 수준의 분리 도를 달성할 수 없었다. 이는 MFUS1 피크 또한 단일 화합물 이 아닐 가능성을 시사하여 준다. Fusarin 구조가 자외선과 고 온에 대하여 화학적으로 불안정하다는 것을 고려한다면 (Gelderblom 등, 1983), 분리 과정에서의 물질 변화 또한 배제 할 수 없을 것이다. Mpfus 1 의 발현 유도를 통하여 $365 \mathrm{~nm}$ 에서 최대 흡수를 보이는 물질 복합체가 생성됨은 $\triangle M p P K S 5$ 균주에 서는 해당 유전자군에 포함된 유전자들의 발현이 이루어지지 않 음을 시사하여 준다.

Fusarium fujikuroi의 fusarin 생합성 연구에서 fusarin fPKSNRPS 유전자 fus 1 이외의 생합성 유전자들을 삭제한 재조합 균 


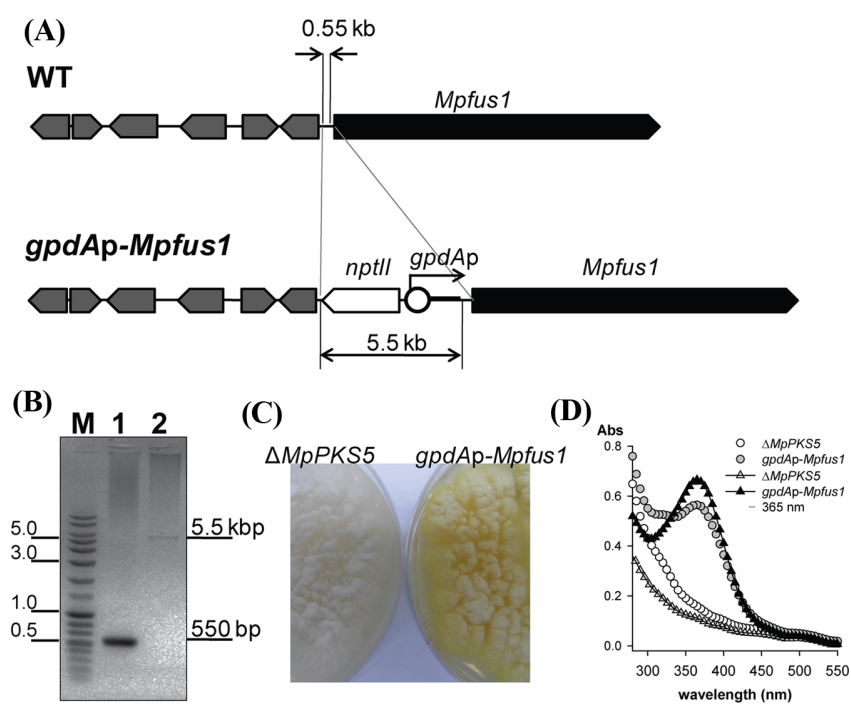

Fig. 3 Induction of Mpfus 1 expression and the resulting phenotypes. (A) Genetic scheme for the generation of gpdAp-Mpfus 1. (B) Analytical PCR results of total DNAs from $\triangle M p P K S 5$ (1) and the gpdAp-Mpfus1 (2) strains. $\mathrm{M}$ indicates a DNA molecular weight marker; 0.5, 1.0, 3.0 and $5.0 \mathrm{~kb}$ highlighted with the bars at the left side. Estimated size of each PCR product is indicated at the right side. (C) Growth of $\triangle M p P K S 5$ and gpdAp-Mpfus 1 on PDA, which is maintained 5 days at 30. (D) Absorption spectra were collected with proper dilutions in methanol. The extracts of $\triangle M p P K S 5$ and gpdAp-Mpfus 1 are represented with unfilled and filled symbols, respectively. Circles represent the methanol extracts; while triangles indicate the samples obtained with chloroform partition of these methanol extracts

주의 경우(Fus1 만이 기능)를 참조하여 $g p d A \mathrm{p}-M p f u s 1$ 균주의 특성을 해석할 수 있다. 해당 F. fujikuroi 균주에서 기대되었던 Fus1 생성물의 선택적 축적 대신 미량 화합물들이 생성되었으 며, 이들에 대한 면밀한 구조 동정 연구를 통하여 이들은 prefusarin과 이들의 산화 변형물들로 확인되었다(Niehaus 등, 2013). gpdAp-Mpfusl 균주에서 관측된 생성물의 이질성은 동일 한 맥락으로 파악할 수 있을 것이며, 두 경우 모두 fPKS-NRPS 생성물이 대사화학적으로 불안정하여 축적이 제한되는 것으로 이해할 수 있다. gpdAp-Mpfus1 균주에서 유도된 화합물에 대한 최소한의 화학 정보를 수집하기 위하여 해당 추출물을 LC-MS 분석에 적용하였다 (Fig. 5). LC-MS 정보 분석은 양성, 음성 이온화 방법을 모두 적용하고 $\triangle M p P K S 5$ 추출물 정보와 상호 비교를 통하여 gpdAp-Mpfus1 추출물에 특이적인 질량 정보를 산출하였다. MFUS1으로 추정되는 피크의 경우 $\mathrm{m} / \mathrm{z} 382.20$ 신 호를 산출하였으며, 이외에 $m / z 416.20,370.16,430.22,398.19$ 등의 신호가 $g p d A \mathrm{p}-M p f u s 1$ 추출물의 화합물 지표로 판단되었 다. 이 중 MFUS1의 분자이온 신호로 추정되는 $m / z 382.20$ 신 호에 대한 collision-induced dissociation (CID) 신호는 $\mathrm{m} / \mathrm{z}$ 276.1로 측정되었다.

\section{MpFus1 생성물의 구조 추론}

Fusarin 계열 화합물들은 2-pyrrolidone 구조와 conjugated polyene 구조를 갖고 있다. 이들 화합물 그룹에서 fusarin 이외 에 발암물질 NG-391을 예로 고려할 수 있으며(Fig. 2), 이들의

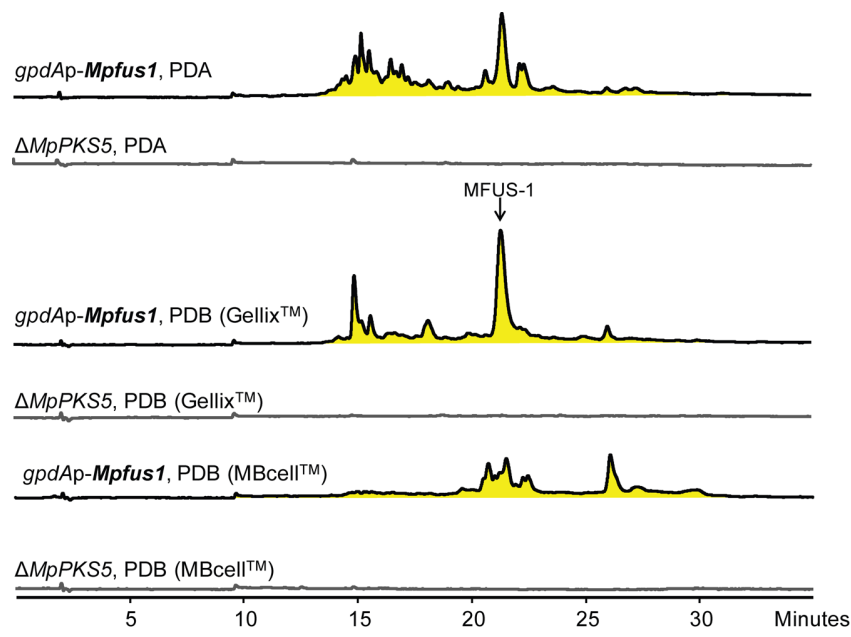

Fig. 4 HPLC analysis of the organic extracts of $\triangle M p P K S 5$ and gpdApMpfus 1 grown on PDA or the PDB submerged culture. PDB media were obtained from two commercial sources; Gellix ${ }^{\mathrm{TM}}$ from Ventech Bio, Korea and MBcell ${ }^{\mathrm{TM}}$ from Kisan Bio, Korea. The HPLC traces were monitored at $350 \mathrm{~nm}$ and are drawn to the same scale. The peak for a hypothetical main product MFUS1 is indicated with an arrow above the chromatogram

생합성은 환원 방출 도메인을 갖춘 $\mathrm{fPKS}-\mathrm{NRPS}$ 에 의하여 그 탄 소 골격이 생성된다(Donzelli 등, 2010; Niehaus 등, 2013). 환 원 방출 활성은 azaphilone 생합성에서 규명되었으며 생성물은 aldehyde 작용기를 갖고 있다(Zabala 등 2012). 그러나 fusarin 생합성의 경우 alcohol 작용기를 갖고 있는 prefusarin이 분리된 것에 근거하여 환원 방출 활성이 두 단계 환원(4개의 전자)을 통하여 alcohol 작용기를 생성하는 것으로 제안되었다(Niehaus 등, 2013). 이와 같은 두 단계 환원 방출 현상은 myxochelin과 myxalamid 등의 생합성에서 그 선례를 찾을 수 있으나 $(\mathrm{Li}$ 등, 2008; Barajas 등, 2015), 이들 화합물의 경우 alcohol 작용기가 최종 화합물에 존재한다는 차이점이 있다. 유기화학적 측면을 고려할 때, aldehyde 작용기에서 2-pyrrolidone 유도체들로의 전 환 기작을 용이하게 추론할 수 있음에 주목할 필요가 있다(Fig. 6). 구체적으로 aldehyde 가상 중간체 1은 aldol condensation 반응을 통하여 2와 3으로 변할 수 있고 이들 구조에서 알려진 fusarin 화합물들의 구조를 추론하는 것이 가능하다. 구조 1 에서 2, 그리고 3 으로의 변환 과정은 비효소적 진행이 가능할 것으 로 추론된다. 따라서 prefusarin이 Fus1의 직접적인 생성물이 아 니며, 세포 내 변형 산물일 가능성을 고려할 필요가 있다.

MFUS1의 질량 분석에서 검출된 $m / z$ 값은 382.20 이며, 해당 양이온이 $\mathrm{Na}^{+}$부가물 형태임을 결정하는 것은 음이온 $\mathrm{m} / \mathrm{z}$ 값 358.20 을 확인하여 가능하였다. 이상의 질량 분석 결과를 통하 여 MFUS1의 질량을 359.21로 추론하였다. gpdAp-Mpfus1 추출 물에서 관찰된 다른 물질들의 경우 MFUS1의 경우와 같이 양 이온, 음이온 질량 분석 결과를 종합하여 분자량이 347.17 , $375.20,393.21,407.23$ 에 해당할 것으로 추론되며, MFUS1에서 유래한 화합물들로 추정된다. 추론된 MFUS1의 질량은 prefusarin 질량에서 $\mathrm{CH}_{4}$ 질량을 감하여 얻을 수 있는 값이다. Fusarin에 비하여 methyl 잔기가 결여된 NG-391 구조의 가상적 인 aldehyde 중간체를 고려하면 해당 질량을 설명할 수 있다 
(A)

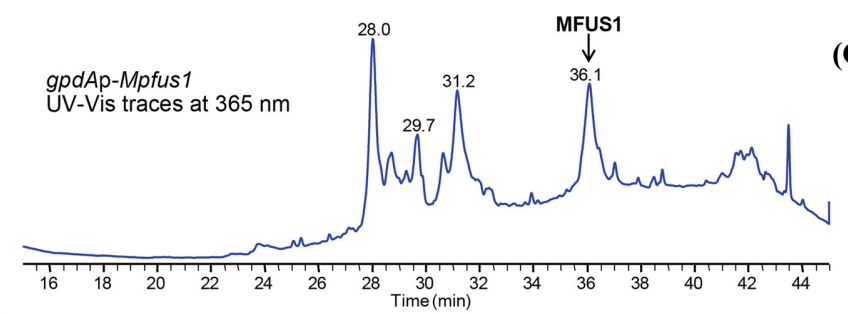

(B)

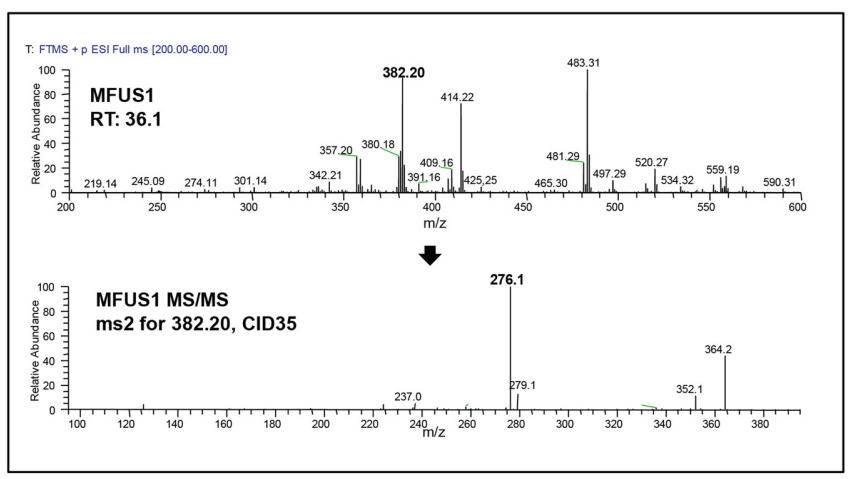

(C)
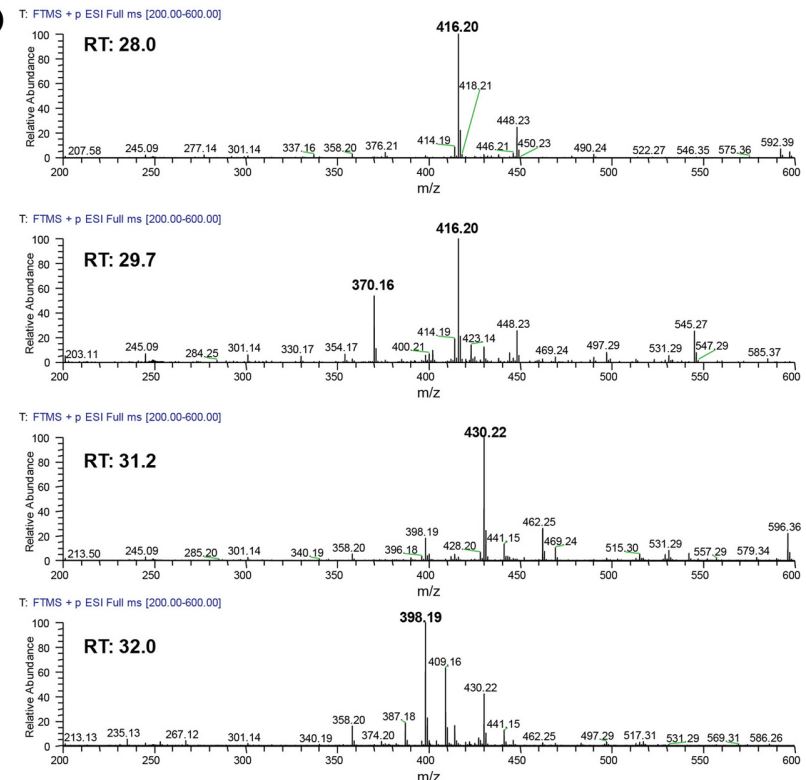

Fig. 5 LC-MS analysis of the gpdAp-Mpfus 1 extract. (A) UV-Vis absorption trace at $365 \mathrm{~nm}$. (B) Positive electrospray mass spectrum for MFUS1 and collision-induced dissociation spectrum of the hypothetical molecular ion of $m / z$ 382.20. (C) Positive electrospray mass spectra of other relevant peaks with their respective retention time shown in $(\mathrm{A})$

NG-391 fPKS-NRPS<smiles>C/C=C(C)\C=C(/C)C=C/C=C/C=C/C(C)=C(/C)C(=O)CC(=O)NC(CCO)CC(=O)C1C(=O)NC(CCO)C1O</smiles>

Hypothetical NG-391 intermediate<smiles>C/C=C\C=C(/C)C(=O)CC(=O)NC(C=O)CCO</smiles>

\section{Fus1 fPKS-NRPS}

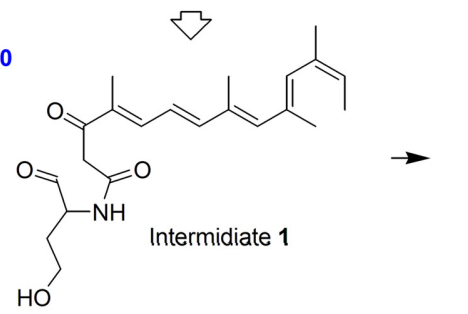<smiles>CC=C(C)C(=O)C1C(=O)NC(CCO)C1O</smiles><smiles>CC=C(C)C(=O)C1=CC(CCO)NC1=O</smiles><smiles>CC=CC(=O)C1C(=O)NC2(O)CCOC12</smiles>

Fusarin A<smiles>CC=C(C)C(=O)C(=O)C1C(=O)N[C@](O)(CCO)[C@@H]1O</smiles>

Dihydrofusarin C

$$
\downarrow[O]
$$<smiles>CC=CC(=O)C1(O)C(=O)NC2(O)CCOC21C(=O)C(C)C</smiles>

Fusarin D

Fusarin C

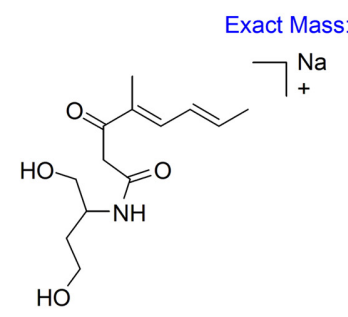

Fig. 6 Proposed mechanism for 2-pyrrolidone moiety formation in fusarin biosynthesis and the structure of a hypothetical NG-391 intermediate related to the proposed MFUS1 structure. Exact mass values of the relevant structures are provided 
(Fig. 6). 즉, $\mathrm{m} / \mathrm{z} 382.20$ 이온은 NG-391의 가상 aldehyde 중 간체(4 또는 5)의 예측 질량에 일치한다. Prefusarin의 CID $\mathrm{MS} / \mathrm{MS}$ 에서 $\mathrm{m} / \mathrm{z}$ 278.1의 딸이온이 보고된 바 있으며, 해당 이 온은 peptide 잔기를 포함하는 부위에서 유래하는 것으로 제안 되었다(Fig. 6; Niehaus 등, 2013)., MFUS1 m/z 382.20 이온 의 $\mathrm{CID} \mathrm{MS/MS}$ 에서 $m / z$ 276.1의 딸이온을 확인하였으며 이는 제안된 MFUS1의 구조(4 또는 5)에 일치하는 결과이다(Fig. 6) 이상의 결과를 통하여 Mpfus1 유전자군은 NG-391 유사 구조 의 생합성을 지정하는 것으로 제안할 수 있다.

본 연구에서 홍국 M. purpureus의 유전체에서 fusarin 유사물 질의 생합성 능력이 잠재되어 있음을 실증하였다. 해당 물질의 구조를 결정하지 못한 부분은 아쉬움으로 남지만, 홍국 균주에 잠재된 미지 생리활성 성분 발굴 가능성을 시사하여 준다는 점 에서 본 연구의 가치를 찾을 수 있을 것이다. Mpfus1 유전자군 은 통상적인 배양 조건에서 발현하지 않는 것으로 판단되며, 향 후 Mpfus1 유전자군의 발현을 유도하는 조건을 찾는 것은 매 우 흥미로운 연구가 될 수 있을 것이다.

\section{초 록}

박테리아와 진균의 유전체 정보 탐색을 통하여 이차대사 생합 성을 지정하는 다수의 잠재 유전자군을 찾을 수 있으며, 유전 체 정보를 기반으로 특정 유전자의 발현을 활성화하여 잠재 유 전자군의 생성물을 추론하고, 해당 물질의 생물학적 기능을 연 구하는 것이 가능하다. 동아시아 지역에서 잘 알려진 식용 사 상진균 홍국에 대하여 몇 몇 유전체 정보가 공개되어있으며, 본 연구에서는 Monascus purpureus $\triangle M p P K S 5$ 균주에서 polyketide synthase-nonribosomal peptide synthase 유전자 Mpfus1 상단에 Aspergillus gpdA 프로모터를 삽입하는 방식으로 이 유전자의 발현을 활성화하였다. Mpfus1 유전자군은 2-pyrrolidone/conjugated polyene 구조를 갖는 물질의 생합성 유전자군들과 높은 유사성 을 보이며, 이들 화합물 그룹에서 진균 독소인 fusarin이 잘 알 려져 있다. $\triangle M p P K S 5$ 균주는 홍국 azaphilone 색소 생산 능력 이 소실된 균주이며 색소 및 자외선 흡수 특성을 보이는 화합 물들의 동정에 적절한 균주이다. Mpfus 1 활성화는 균사체가 노 란색을 띠도록 유도하며, 균사체의 methanol 추출액은 $365 \mathrm{~nm}$ 에서 최대 흡광도를 보임을 확인할 수 있었다. 해당 추출액의 HPLC 분석을 통하여 다수의 화합물들이 포함되어 있음을 확인 할 수 있었으며 이를 통하여 MpFus1 효소의 생성물이 대사적, 화학적으로 불안정함을 추론할 수 있다. Mpfusl 활성화 균주 추출물을 LC-MS로 분석하여 MpFus1 생성물의 구조를 유추하 여 Mpfus 1 유전자군이 fusarin의 탈메틸 유사체 생합성을 지정 하는 것으로 제안할 수 있었다. 본 연구는 홍국 균주에서 유전 체 기반-미지 화합물 발굴 연구의 예를 제시하고 홍국 균주에 서 새로운 생리활성의 동정 가능성을 시사하여 준다.

Keywords 이중교차 유전자 치환 - 잠재 유전자의 발현 유도 홍국 Monascus purpureus · Aspergillus gpdA 프로모터 · Fusarin 유사체 · Polyketide synthase-nonribosomal peptide synthase 하이브리드
감사의 글 이 논문은 2018 년도 정부(교육부)의 재원으로 한국연구재단의 지원을 받아 수행된 기초연구사업임(NRF-2016R1D1A1B02009237).

\section{References}

Balakrishnan B, Chandran R, Park SH, Kwon HJ (2016) Delineating citrinin biosynthesis: Ctn-ORF3 dioxygenase-mediated multi-step methyl oxidation precedes a reduction-mediated pyran ring cyclization. Bioorg Med Chem Lett 26: 392-396

Balakrishnan B, Chen CC, Pan TM, Kwon HJ (2014) Mpp7 controls regioselective Knoevenagel condensation during the biosynthesis of Monascus azaphilone pigments. Tetrahedron Lett 55: 1640-1643

Balakrishnan B, Karki S, Chiu SH, Kim HJ, Suh JW, Nam B, Yoon YM, Chen CC, Kwon HJ (2013) Genetic localization and in vivo characterization of a Monascus azaphilone pigment biosynthetic gene cluster. Appl Microbiol Biotechnol 97: 6337-6345

Balakrishnan B, Lim YJ, Hwang SH, Lee DW, Park SH, Kwon HJ (2017a) Selective production of red azaphilone pigments in a Monascus purpureus mppDEG deletion mutant. J Appl Biol Chem 60: 249-256

Balakrishnan B, Park SH, Kwon HJ (2017b) A reductase gene mppE controls yellow component production in azaphilone polyketide pathway of Monascus. Biotechnol Lett 39: 163-169

Balakrishnan B, Park SH, Kwon HJ (2017c) Inactivation of the oxidase gene mppG results in the selective loss of orange azaphilone pigments in Monascus purpureus. Appl Biol Chem 60: 437-446

Barajas JF, Phelan RM, Schaub AJ, Kliewer JT, Kelly PJ, Jackson DR, Luo R, Keasling JD, Tsai SC (2015) Comprehensive structural and biochemical analysis of the terminal myxalamid reductase domain for the engineered production of primary alcohols. Chem Biol 22: 1018 1029

Bijinu B, Suh JW, Park SH, Kwon HJ (2014) Delineating Monascus azaphilone pigment biosynthesis: oxidoreductive modifications determine the ring cyclization pattern in azaphilone biosynthesis. RSC Adv 4: 59405-59408

Boettger D, Hertweck C (2013) Molecular diversity sculpted by fungal PKSNRPS hybrids. Chembiochem 13: 28-42

Chen W, Chen R, Liu Q, He Y, He K, Ding X, Kang L, Guo X, Xie N, Zhou Y, Lu Y, Cox RJ, Molnár I, Li M, Shao Y, Chen F (2017) Orange, red, yellow: biosynthesis of azaphilone pigments in Monascus fungi. Chem Sci 8:4917-4925

Chen W, He Y, Zhou Y, Shao Y, Feng Y, Li M, Chen F (2015) Edible flamentous fungi from the species Monascus: Early traditional fermentations, modern molecular biology, and future genomics. Compr Rev Food Sci Food Safety 14: 555-567

Chiang YM, Oakley BR, Keller NP, Wang CC (2010) Unraveling polyketide synthesis in members of the genus Aspergillus. Appl Microbiol Biotechnol 86: 1719-1736

Cox RJ (2007) Polyketides, proteins and genes in fungi: programmed nanomachines begin to reveal their secrets. Org Biomol Chem 5: 2010-2026

de Groot MJ, Bundock P, Hooykaas PJ, Beijersbergen AG (1998) Agrobacterium tumefaciens-mediated transformation of filamentous fungi. Nat Biotechnol 16: 839-842

Díaz-Sánchez V, Avalos J, Limón MC (2012) Identification and regulation of fusA, the polyketide synthase gene responsible for fusarin production in Fusarium fujikuroi. Appl Environ Microbiol 78: 7258-7266

Donzelli B, Krasnoff S, Churchill A, Vandenberg J, Gibson D (2010) Identification of a hybrid PKS-NRPS required for the biosynthesis of NG-391 in Metarhizium robertsii. Curr Genet 56: 151-162

Fisch KM (2013) Biosynthesis of natural products by microbial iterative hybrid PKS-NRPS. RSC Adv 3: 18228-18247

Gelderblom WCA, Thiel PG, Van der Merwe KJ, Marasas WFO, Spies HSC (1983) A mutagen produced by Fusarium moniliforme. Toxicon 21: $467-473$ 
Kwon HJ, Balakrishnan B, Kim YK (2016) Some Monascus purpureus genomes lack the monacolin K biosynthesis locus. J Appl Biol Chem 59 45-47

Li Y, Weissman KJ, Muller R (2008) Myxochelin biosynthesis: direct evidence for two-and four-electron reduction of a carrier protein-bound thioester. J Am Chem Soc 130: 7554-7555

Medema MH, Fischbach MA (2015) Computational approaches to natural product discovery. Nat Chem Biol. 11: 639-648

Namiki F, Matsunaga M, Okuda M, Inoue I, Nishi K, Fujita Y, Tsuge T (2001) Mutation of an arginine biosynthesis gene causes reduced pathogenicity in Fusarium oxysporum f. sp. melonis. Mol. Plant-Microbe Interact 14: 580-584

Niehaus EM, Kleigrewe K, Wiemann P, Studt L, Sieber CM, Connolly LR, Freitag M, Güldener U, Tudzynski B, Humpf HU (2013) Genetic manipulation of the Fusarium fujikuroi fusarin gene cluster yields insight into the complex regulation and fusarin biosynthetic pathway. Chem Biol
20: 1055-1066

Patakova P (2013) Monascus secondary metabolites: production and biological activity. J Ind Microbiol Biotechnol 40: 169-181

Redkar RJ, Herzog RW, Singh NK (1998) Transcriptional activation of the Aspergillus nidulans gpdA promoter by osmotic signals. Appl Environ Microbiol 64: 2229-2231

van der Lee TAJ, Medema MH (2016) Computational strategies for genomebased natural product discovery and engineering in fungi. Fungal Genet Biol 89: 29-36

Yin Y, Cai M, Zhou X, Li Z, Zhang Y (2016) Polyketides in Aspergillus terreus: biosynthesis pathway discovery and application. Appl Microbiol Biotechnol 100: 7787-7798

Zabala AO, Xu W, Chooi YH, Tang Y (2012) Characterization of a silent azaphilone gene cluster from Aspergillus niger ATCC 1015 reveals a hydroxylation-mediated pyran-ring formation. Chem Biol 19: 1049-1059 